\title{
Relations between serial and paired-associate learning in children
}

\author{
SUSAN G. WALKER and LEWIS P. LIPSITT \\ Brown University, Providence, Rhode Island 62912
}

\begin{abstract}
Fourth grade subjects learned a serial list of six words, then a paired-associate list of six word pairs. The first three words of the serial task became correct responses for three PA pairs, while other PA words were new. Significant negative transfer was obtained for those PA pairs containing responses from the serial list. While serial and PA learning were not correlated, both serial and PA learning were significantly correlated with IQ.
\end{abstract}

Serial learning (SL) and paired-associate learning (PAL) tasks have been used to study rote verbal learning. Association models have been suggested for both procedures (e.g., Ebbinghaus, 1885; Underwood \& Schulz, 1960). However, PAL appears also to involve a response learning stage which precedes the association stage (Underwood \& Schulz, 1960). Both response learning and specific associations can transfer from a SL task to a subsequent PA task, but serial to paired-associate transfer experiments have yielded ambiguous findings.

A six-word serial task was followed in the present study by a list of six PA items. The first three words of the serial task became responses for three of the PA pairs, but all other words for the PA list were new. Those PA pairs with responses from the serial list should produce negative transfer (A-B, C-B); those with new responses should be neutral (A-B, C-D). It is conceivable, however, that some positive transfer could occur in the A-B, C-B pairs through facilitative response pretraining.

The A-B, C-B design used here is thought to be a weaker transfer design than A-B, A-Br (Porter \& Duncan, 1953), and it has rarely been used in SL-PAL transfer research. However, Giurintano (1973) did use it and obtained apparent negative transfer in adults.

\section{METHOD}

\begin{abstract}
Apparatus
A Kodak Carousel projector, Model 800 , with automatic presentation timer, was used to project slides on a wall $7 \mathrm{ft}$ away. Slides were made of Mylar drafting film on which words were typed with an IBM Selectric typewriter. Words used were concrete nouns chosen from Palermo and Jenkins (1964), and none had any listed associations with any of the others.
\end{abstract}

This study was conducted as a Senior Honors Thesis by Susan G. Walker (1972) under the direction of Lewis P. Lipsitt. The authors thank especially Mildred $H$. Aitken, principal of the Newman Avenue School, and Francis W. Gallishaw, superintendent of the Seekonk, Massachusetts Public Schools for their cooperation. Thanks also to David $O$. Robinson for statistical help.

Reprints from L. P. Lipsitt, Department of Psychology, Brown University, Providence, Rhode Island 02912.
Table 1

Paired-Associate Pairs and Experimental Design

\begin{tabular}{|c|c|c|c|c|c|c|}
\hline \multicolumn{2}{|l|}{$\begin{array}{l}\text { 1. scissor-lamp } \\
\text { 2. hammer-stove } \\
\text { 3. lion-cabbage }\end{array}$} & \multicolumn{3}{|c|}{$\begin{array}{l}\text { 4. soldier-window } \\
\text { 5. eagle-carpet } \\
\text { 6. child-blossom }\end{array}$} & \multicolumn{2}{|c|}{$\begin{array}{l}\text { 7. city-spider } \\
\text { 8. bed-cheese } \\
\text { 9. stomach-thief }\end{array}$} \\
\hline \multicolumn{7}{|c|}{$\begin{array}{l}\text { Assignment of Words to Each of the Counterbalancing Groups } \\
\text { Group } 1\end{array}$} \\
\hline & SL & PAL & SL & PAL & SL & PAL \\
\hline Transfer & $\begin{array}{l}R_{1} \\
R_{2} \\
R_{3}\end{array}$ & $\begin{array}{l}S_{1}-R_{1} \\
S_{2}-R_{2} \\
S_{3}-R_{3}\end{array}$ & $\begin{array}{l}R_{4} \\
R_{5} \\
R_{6}\end{array}$ & $\begin{array}{l}S_{4}-R_{4} \\
S_{5}-R_{5} \\
S_{6}-R_{6}\end{array}$ & $\begin{array}{l}\mathrm{R}_{7} \\
\mathrm{R}_{8} \\
\mathrm{R}_{9}\end{array}$ & $\begin{array}{l}S_{7}-R_{7} \\
S_{8}-R_{8} \\
S_{9}-R_{9}\end{array}$ \\
\hline Control & $\begin{array}{l}R_{4} \\
R_{5} \\
R_{6}\end{array}$ & $\begin{array}{l}\mathrm{S}_{7}-\mathrm{R}_{7} \\
\mathrm{~S}_{8}-\mathrm{R}_{8} \\
\mathrm{~S}_{9}-\mathrm{R}_{9}\end{array}$ & $\begin{array}{l}\mathrm{R}_{7} \\
\mathrm{R}_{8}\end{array}$ & $\begin{array}{l}S_{1}-R_{1} \\
S_{2}-R_{2} \\
S_{3}-R_{3}\end{array}$ & $\begin{array}{l}R_{1} \\
R_{2} \\
R_{3}\end{array}$ & $\begin{array}{l}S_{4}-R_{4} \\
S_{5}-R_{5} \\
S_{6}-R_{6}\end{array}$ \\
\hline
\end{tabular}

\section{Experimental Design}

The transfer design necessitated that each subject first learn a serial list of six words, then a PA list of six word pairs. The first three words of the serial task became responses for three of the PA pairs, while all other words on the PA list were new. Three counterbalancing groups (see Table 1) were used so that the familiarized responses (those from the SL relevant to the PA list) and the PA pairs in which they occurred were both counterbalanced. Also, any differences in the ease of learning the responses, or the associations between the stimuli and responses, were controlled by the use of nine different PA pairs, as shown in Table 1.

\section{Subjects}

As the 45 fourth graders were sent individually from their rooms by their teachers, 15 were assigned to each counterbalancing group in a cyclic manner. The third-grade Kuhlmann-Anderson IQ scores ranged from 77 to 140 . Although the counterbalancing groups were not deliberately equated on IQ, they had comparable mean (Group 1 , mean IQ $=105.5, \mathrm{SD}=$ 12.9; Group 2, mean IQ $=106.9, \mathrm{SD}=12.6$; Group 3, mean IQ $=$ 107.9, $\mathrm{SD}=14.1$ ).

\section{Procedure}

One slide tray was used for each group, each containing three copies of the serial list and four random orders of the PA list. The first word of the serial task was preceded by an asterisk, and the anticipation method was used for both tasks. Each slide was shown for $5 \mathrm{sec}$. The intertrial interval was $10 \mathrm{sec}$. The trays were rotated to the starting point to accommodate additional trials for each task as required. This took approximately $10 \mathrm{sec}$.

All subjects were tested individually. A criterion of either one 
errorless run through the list, or 20 trials, was used for both lists. Instructions for SL were as follows:

"I am interested in seeing how people learn things in order. I am going to show you slides of six words, one after another. You learn what order the six words are in. When you see the first slide, I want you to tell me what will be on the second slide. When you see the second slide, you tell me what will be on the third and so on. Here I'll show you an example using letters. (Demonstration cards shown and explained). Any questions? OK, here we go."

Immediately following SL, the PAL instructions were administered and testing proceeded:

"Now, we'll do something different. This time you don't learn the words in order. All you do is learn which two words go together. The first slide will have one word and the second will have two-the same word and another one besides. Those two words go together. When you see the first word, you say what word goes with it, and the next slide will show you if you are right. Here's an example using letters. (Demonstration cards shown and explained.) Any questions? OK, let's start."

Examples were shown on index cards. Letters were used to minimize transfer from the examples to the lists. The serial example consisted of letters "L," "C," and "F" in that order, and the PA examples were "P-D" and "G-X."

After all subjects had been tested, the third grade IQ scores on the Kuhlmann-Anderson Intelligence Test were obtained from the school principal.

\section{RESULTS AND DISCUSSION}

\section{Transfer Effects}

A significant negative transfer effect was obtained. A faster learning rate occurred for those PA pairs with new responses than those with words appropriated from the SL task. In a mixed-design analysis of variance over the PAL errors-to-criterion data, with counterbalancing groups as a between-subjects and pair type as a within-subjects variable, negative transfer was highly reliable $[F(1,46)=15.59, p<.001]$. Neither the main effect of counterbalancing nor the Counterbalancing by Pair Type interaction was significant. The overall mean number of errors-to-criterion for the transfer pairs was $10.02(\mathrm{SD}=8.51)$, and the mean for the control pairs was $7.82(\mathrm{SD}=8.66)$.

An analysis relating the serial position of the familarized responses, which were always in the first three positions in SL, to performance on the relevant transfer pairs in PAL found an apparent effect of greater interference for the first position $(\overline{\mathrm{X}}=6.47$ trials to criterion), then the second $(\overline{\mathrm{X}}=6.11)$, and finally the third $(\overline{\mathrm{X}}=5.47)$, but the effect was not reliable.

A PAL interference score $(\Sigma \mathrm{T}-\Sigma \mathrm{C}+8$, where $\mathrm{T}$ is number of trials to criterion for transfer pairs and $\mathrm{C}$ for control pairs, and +8 eliminates negative scores) for each subject provided a specific measure of interference separate from trials to criterion for either the serial or PA lists. Correlation of this PAL interference score with trials to criterion for the serial list resulted in a nonsignificant Pearson $\mathrm{r}$ of $.23(\mathrm{df}=43)$. The number of trials spent learning the SL task thus did not affect amount of negative transfer. Moreover, the overall criterion measure on the PA list was not related to these interference scores: $\mathrm{r}=-.06$. $\mathrm{A}$ correlation of interference scores with IQ produced a Pearson $\mathrm{r}$ of .27 , just short of significance.

No evidence of positive transfer due to response learning was found. The transfer pairs showed poorer performance even on the second trial, which was the first trial on which the subjects responded. Sandler's A showed a significant negative transfer effect at that point. Collapsing over groups, the obtained A was .49, $\mathrm{p}<.01$.

The strong negative interference effect is interesting in light of the conflicting results from SL-to-PAL transfer studies using the often stronger $\mathrm{A}-\mathrm{B}, \mathrm{A}-\mathrm{Br}$ design. The present study used concrete nouns as stimuli while many previous studies have used adjectives. Crowder (1966) and Crowder, Chisholm, \& Fell (1968), studies which did find negative transfer, also used nouns. Finally, the age of the subject could be a factor; most other studies have used college students. Possibly children are more affected by competing associations formed during SL.

\section{Comparisons Among SL, PAL, and IQ}

Absence of a strong relationship between SL and PAL performance has been reported for college students by Jensen (1962). Here as well, SL and PAL performance measures were not significantly related. A correlation between trials to criterion of SL and PAL yielded a Pearson $\mathrm{r}$ of only .12. Interestingly, however, each of these measures was significantly correlated with third-grade IQ. The obtained Pearson $r$ between PAL trials to criterion and IQ was $-.42(\mathrm{p}<.01)$ and that between SL and IQ was $-.51(\mathrm{p}<.001)$. These latter effects replicate Jensen's (1965) findings of a positive relationship between IQ and performance on both types of learning tasks in adults.

\section{REFERENCES}

Crowder, R. G. Evidence for the chaining hypothesis of serial verbal learning. Journal of Experimental Psychology, 1968 , 76, 497-500.

Crowder, R. G., Chisholm, D. D., \& Fell, D. A. Transfer from serial to continuous paired-associate learning. Psychonomic Science, 1966, 6, 455-456.

Ebbinghaus, H. Memory: A contribution to experimental psychology. Orig. Publ. 1885, translated by H. A. Pryer and C. E. Bussenius.) New York: Dover, 1964

Giurintano, S. L. Serial learning processes: test of chaining, position and dual-process hypotheses. Journal of Experimental Psychology, 1973, 97, 154-157.

Jensen, A. R Transfer between paired-associate and serial learning. Journal of Verbal Learning and Verbal Behavior, 1962, 1, 269-280.

Jensen, A. R. Rote learning in retarded adults and normal children. Journal of Mental Deficiency, 1965, 69, 828-834.

Palermo, D. S. \& Jenkins, J. J. Word association norms: grade school through college. Minneapolis: University of Minnesota Press, 1964.

Porter, $L$. W. \& Duncan, C. P. Negative transfer in verbal learning. Journal of Experimental Psychology, 1953, 46, learnin.

Underwood, B. J., \& Schulz, R. W. Meaningfulness and verbal learning. Chicazo: Lippincott, 1960.

Walker, S. G. Serial and paired associate learning in fourth graders. Brown University, Honors Thesis, 1972. 